\title{
Utility of a psychological framework for carnivore conservation
}

\author{
Neil H. Carter, Shawn J. Riley and Jianguo Lie
}

\begin{abstract}
Conserving threatened carnivore species increasingly depends on the capacity of local people to cohabit with those species. To examine such capacity we developed a novel psychological framework for conservation in regions of the world where there are human-carnivore conflicts, and used the Endangered tiger Panthera tigris to explore the utility of this framework. Specifically, we tested three hypotheses in Chitwan National Park, Nepal, where increasing human-tiger conflicts potentially jeopardize long-term coexistence. We administered a survey to 499 individuals living $<_{2} \mathrm{~km}$ from the Park and in nearby multiple-use forest, to record preferred future tiger population size and factors that may influence preferences, including past interactions with tigers (e.g. livestock predation) and beliefs and perceptions about tigers. Over $17 \%$ of respondents reported that a tiger had attacked their livestock or threatened them directly. Results from a structural equation model indicated that respondents who preferred fewer tigers in the future were less likely to associate tigers with beneficial attributes, more likely to associate tigers with undesirable attributes, and more likely to believe that government officials poorly manage tiger-related risks and that people are vulnerable to risks from tigers. Our framework can help address current and future conservation challenges because it (1) integrates an expansive and generalized set of psychological concepts, (2) enables the identification of conservation interventions that foster coexistence between people and carnivores, and (3) is suitable for broad application.
\end{abstract}

Keywords Belief, human-carnivore conflict, Nepal, Panthera tigris, perception, psychological framework, risk, tiger

\section{Introduction}

Competition between humans and carnivores over limited resources, such as space and food, often leads to human-carnivore conflicts. These conflicts occur

\footnotetext{
NeIL H. Carter (Corresponding author) and Jianguo Liu Center for Systems Integration and Sustainability, Michigan State University, 115 Manly Miles Building, East Lansing, Michigan 48824, USA. E-mail cartern7@msu.edu

SHAwn J. Riley Department of Fisheries and Wildlife, Michigan State University, East Lansing, Michigan, USA

Received 30 September 2011. Revision requested 9 January 2012.

Accepted 17 February 2012. First published online 31 July 2012.
}

worldwide, and are increasing in regions where human land-uses, driven by population growth, are expanding and intensifying (Treves \& Karanth, 2003; Inskip \& Zimmermann, 2009). Human-carnivore conflicts are defined here as direct threats to the economic (e.g. livestock depredation), health and safety (e.g. transmission of disease, attacks on people), and psychological (e.g. fear of attack) well-being of people (Woodroffe et al., 2005). A common reaction to real or perceived conflicts is to reduce carnivore populations (Woodroffe \& Ginsberg, 1998). Responses range from individual people killing specific animals to governments sanctioning large-scale carnivore eradications. For example, in the 19th and 2oth centuries eradication programmes nearly extirpated wolves Canis lupus and cougar Puma concolor from the contiguous United States to relieve negative effects of these species on livestock (Woodroffe, 2000). Similarly, beginning in the 1950s, tigers were subjected to uncontrolled killing in China after the government declared tigers a pest (Seidensticker et al., 1999). More recently, several conflict-prone carnivore species, including African wild dog Lycaon pictus, spotted hyaena Crocuta crocuta and grizzly bear Ursus arctos horribilis have declined because of human persecution (Woodroffe, 2001).

The long-term viability of threatened carnivores is significantly jeopardized when local people take action to eliminate so-called problem animals (e.g. by poisoning them). Human-caused mortality affects carnivore population dynamics by creating population sinks and decreasing the probability of population persistence (Woodroffe \& Ginsberg, 1998). The extent and degree of these impacts on carnivore populations are substantial as much of the remaining range of threatened carnivores is on humandominated land (Dickman et al., 2011).

Sustaining threatened carnivore species therefore depends on the capacity of local people to tolerate carnivorerelated risks and to desire increasing or expanding carnivore populations or, at the very least, policy favourable to their conservation (Riley \& Decker, 200ob). The capacity of local people to cohabit with wildlife is strongly influenced by subjective psychological factors, including beliefs and perceptions (Decker \& Purdy, 1988; Riley \& Decker, 200ob; Zinn et al., 2000; Bruskotter et al., 2009). Several studies have assessed these factors independently with respect to threatened carnivores in various regions (Saberwal et al., 1994; Marker et al., 2003; Romañach et al., 2007) but none of these studies integrated psychological concepts into a comprehensive framework. 
We developed a novel psychological framework for conservation in regions of the world where there are human-carnivore conflicts, and used the tiger Panthera tigris to explore the utility of this framework. We evaluated the effects of past interactions with tigers as well as beliefs and perceptions towards tigers on preferred future tiger population size among people living near Chitwan National Park, Nepal, where there is an increasing frequency of human-tiger conflicts (Gurung et al., 2008).

Our research is the first quantitative evaluation of the relationships between past interactions with carnivores, psychological concepts and preferred future carnivore population size. Our psychological framework integrates a comprehensive and generalized set of concepts, allowing researchers systematically to test hypotheses and develop theories regarding the ways people relate to carnivores under a wide range of conditions. The framework also facilitates the identification of interventions with the greatest effect on preferences for carnivores.

\section{Psychological framework}

In our framework, an individual's personal experience or interactions with carnivores affects his or her beliefs and perceptions associated with these species, which, in turn, affects his or her preferences for population sizes (Fig. 1).

\section{Past interactions with carnivores}

Personal interactions with carnivores may occur in places where humans and carnivores live in close proximity. We defined these interactions as direct, including predation of livestock and encounters between people and carnivores in the wild (e.g. carnivore scat or pugmark seen, carnivore seen or heard, person attacked; Saberwal et al., 1994; Wang et al., 2006). In addition to direct interactions, theory about the social amplification of risk posits that interpersonal connections and media outlets amplify risk signals (i.e. intensify information about risk) regarding a particular event or interaction (Kasperson et al., 1988). We defined these interactions as indirect, including hearing or reading news about human-carnivore encounters from the media or personal contacts (Gore \& Knuth, 2009). Several studies demonstrate that direct and indirect interactions with carnivores affect cognitions (e.g. beliefs) and emotions (e.g. worries) towards the carnivore species (Saberwal et al., 1994; Wang et al., 2006; Gore \& Knuth, 2009).

\section{Beliefs about carnivores and carnivore-related risks}

Beliefs are broadly defined as 'associations or linkages that people establish between the attitude object and various attributes' (Eagly \& Chaiken, 1993). Beliefs mediate the relationships between broad, abstract values (e.g. honesty)

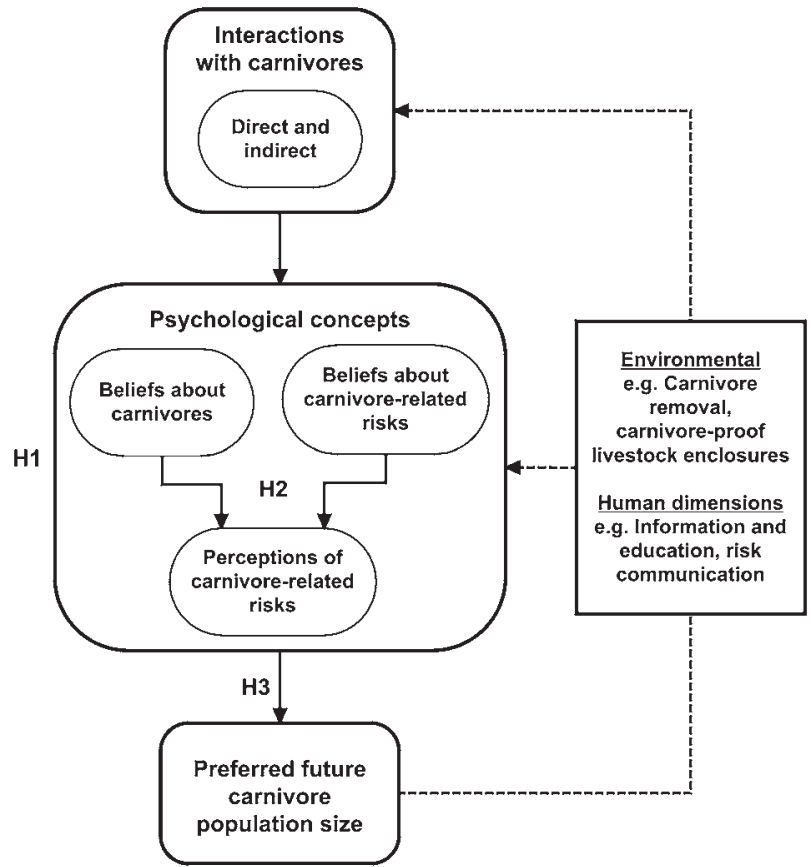

FIG. 1 Psychological framework illustrating relationships between interactions with carnivores, psychological concepts, and preferred future carnivore population size. The dashed lines illustrate potential management actions influencing preferences for carnivores. Management actions include those that affect the physical environment in which carnivores and humans interact and those that affect the human dimensions. The three hypotheses tested are indicated. $\mathrm{H}_{1}$, the effect of past interactions with carnivores on preference for future carnivore population size is mediated by beliefs and perceptions about carnivores; $\mathrm{H}_{2}$, perceptions of carnivore-related risks are strongly influenced by beliefs about carnivores and carnivore-related risks; $\mathrm{H}_{3}$, preferred future carnivore population size is strongly influenced by beliefs about carnivores, carnivore-related risk, and perceptions of those risks.

and behaviour (Fulton et al., 1996). Beliefs about carnivores are based on beneficial and undesirable attributes associated with the species. Benefits associated with carnivores include cultural, religious, economic (e.g. tourism), ecological and existential attributes (Kellert, 1985), whereas nuisance behaviour and resource competition are undesirable attributes (Sharma, 1990; Kissui, 2008). Beliefs about carnivore-related risks are associated with the perceived duration that the individual has been exposed to risk, rate of change in exposure to risks, ability of the individual to adapt to and avoid risks, ability of authorities to understand and address risks, and balance of benefits compared to risks (Slovic, 1987; Sjöberg, 1998; Riley \& Decker, 200ob; Gore et al., 2006).

\section{Perceptions of carnivore-related risks}

Riley \& Decker (2000a) suggested that risk perceptions are a product of an underlying belief system rather than a cause 
of these beliefs. Perceptions of risk towards encounters with carnivores that threaten livelihoods (e.g. carnivore attacks livestock) and safety (e.g. carnivore attacks someone) can be affective or cognitive. Whereas affective risk measures the dread or worry an individual feels towards a specific negative human-carnivore encounter occurring (Sjöberg, 1998; Gore \& Knuth, 2009), cognitive risk estimates the perceived likelihood of the encounter occurring (Riley \& Decker, 2000a). Importantly, perceptions and beliefs are subject to manipulation through information and education (Zinn et al., 2000).

\section{Preferences for future carnivore population size}

According to theories of human cognition (Ajzen, 1991; Fulton et al., 1996) and empirical studies (Fulton et al., 1996; Riley \& Decker, 2000a; Bruskotter et al., 2009; Gore \& Knuth, 2009) beliefs about wildlife, wildlife-related risks, and perceptions of those risks strongly influence an individual's 'acceptance capacity' for wildlife. Wildlife acceptance capacity, first introduced by Decker \& Purdy (1988), was initially defined as the 'maximum wildlife population level in an area acceptable to people', and acknowledged that people have a limited capacity to cohabit with wildlife (Carpenter et al., 2000). We used preference for future carnivore population size to measure an individual's acceptance capacity for carnivores. As human behaviours limit carnivore distribution and population sizes (Woodroffe \& Ginsberg, 1998) the ability to support a carnivore population within any habitat may be as much a function of wildlife acceptance capacity as biological carrying capacity (Riley \& Decker, 2000a). Unlike previous research on wildlife acceptance capacity our study focused on conservation of a threatened carnivore rather than management of abundant wildlife species (Zinn et al., 2000; Whittaker et al., 2006; Lischka et al., 2008).

\section{Hypotheses}

Based on our psychological framework we formulated three hypotheses concerning the relationships between tigers and people living near Chitwan National Park: (1) The effect of past interactions with tigers on preference for future tiger population size is mediated by beliefs and perceptions about tigers. (2) Perceptions of tiger-related risks are strongly influenced by beliefs about tigers and tiger-related risks. (3) Preferred future tiger population size is strongly influenced by beliefs about tigers, tiger-related risk, and perceptions of those risks.

\section{Study area}

Our study site was western Chitwan district to the north of Chitwan National Park (Fig. 2). Chitwan district is located in a river valley basin along the flood plains of the Rapti, Reu and Narayani rivers at altitudes of $150-815 \mathrm{~m}$. The area is subtropical, with a summer monsoon from mid June to late September, and a cool dry winter (Laurie, 1982). Chitwan district has a complex mixture of ethnicities (Axinn \& Ghimire, 2007). Many people there depend on crops and livestock for their livelihood, and rely on nearby forests for thatch, reeds, fodder, fuelwood, timber and other products to support their agricultural lifestyles (Sharma, 1990). Chitwan National Park, established in

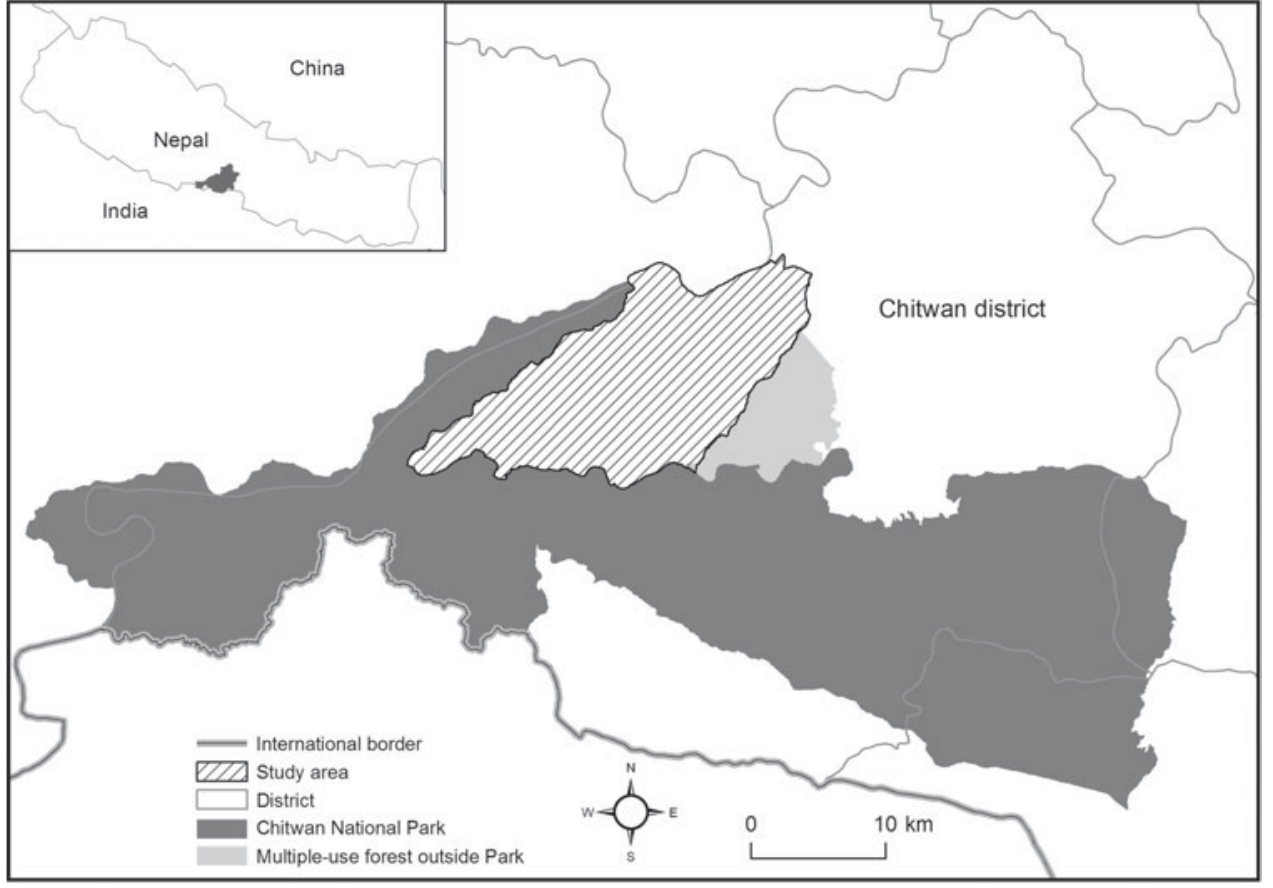

FIG. 2 Location of the study site in Chitwan. The shaded area on the inset indicates the location of Chitwan district in Nepal. 
1973 , is a globally important protected area for conservation of tigers (Walston et al., 2010). At the time of our research the study area comprised a mosaic of land uses, including National Park, National Forest, community forests, agriculture and urban development. In 2001 the human population in the study area was C. 200,000, and the total number of households c. 41,300 (CBS, 2001).

\section{Methods}

\section{Survey design}

In June 2008 we conducted a focus group with 10 people from Chitwan to discuss their beliefs and perceptions about tigers. We used insights from this group to understand the vernacular and modify previously tested survey items, particularly Riley (1998) and Peyton et al. (2001). Local Nepali experienced in social survey research design worked with us to ensure internal validity of our survey measures. We designed a structured survey to record interactions with tigers, beliefs about tigers, beliefs about tiger-related risks, perceptions of tiger-related risks, and preferred future tiger population size, as well as respondent age, ethnicity, gender, education level and occupation. In December 2009 we pre-tested the survey $(\mathrm{n}=17)$ in a site adjacent to our study area, to improve survey effectiveness. Preferred number of tigers living nearby in the next 10 years was based on a 5-point bipolar scale (i.e. much less, less, same, more and much more). We chose 10 years because it is a round number and a conceivable time-frame in which tiger population size can change significantly. All belief questions were binary (i.e. no, yes) or on a 3-point bipolar scale (i.e. less, same, more). All risk perception questions were on a 3-level nominal scale (i.e. none, somewhat, very). 'Don't know' options were provided on all questions.

\section{Sample selection}

Wards (the smallest administrative unit in the district) that had at least $50 \%$ of their area within $1 \mathrm{~km}$ of Chitwan National Park or the multiple-use forest adjacent to the Park, where the majority of human-tiger conflicts occur (Department of National Parks and Wildlife Conservation, unpubl. data), were selected. Ward boundary data were extracted from 1996 digital topographic data obtained from the Nepal Survey Department (NSD, 1996); these are the most recent data and little change in ward boundaries has occurred since. We randomly selected 500 residences within the wards based on residence locations in 1996 $(\mathrm{n}=5,400)$. The number of residences has increased since 1996. In February 2010 the name and age of all persons living in each of the 500 residences (inclusion criterion was that they must have been residing in the house during the week prior to the time when the survey would be administered) were recorded and compiled. From this list a single individual (age 15-59) was randomly selected for survey from each of the 500 residences, resulting in a total of 500 possible respondents. From March to April 2010 trained Nepali interviewers contacted each possible respondent to administer the survey face-to-face.

\section{Data analyses}

We used structural equation modelling (SEM) to assess interrelationships among interactions with tigers, beliefs about tigers and tiger-related risks, perceptions of tigerrelated risks, and preferred future tiger population size as hypothesized in our psychological framework. Unweighted data were used to develop the models. SEM is ideal for evaluating our multi-level framework because it simultaneously measures associations among several independent and dependent variables.

Confirmatory factor analysis, an inherent procedure in SEM, was conducted to assess the degree to which 20 survey items (i.e. observed variables) loaded on four a priori defined latent (unobserved) variables: (1) beliefs about tigers, (2) beliefs about tiger-related risks, (3) perceptions of affective risk, and (4) perceptions of cognitive risk. We constrained each item to load on only one latent factor. The factor analysis could not support missing data (i.e. survey items with 'don't know' responses). We therefore omitted 11 cases $(2.2 \%)$ with missing data from our survey sample using listwise deletion, which is acceptable if the number of cases omitted is $<5 \%$ of the total sample (Schafer, 1999).

Structural equation models measure the direct and indirect effects of variables on one another according to a path diagram. We developed a path diagram that linked a variable we created to describe interactions with tigers to the belief and perception latent variables, and linked these latent variables to preferences for future tiger population size. The variable we created to describe interactions with tigers ranged from 1 (very low) to 5 (very high). Category 1 (very low) included respondents who indicated no direct or indirect interactions with tigers, category 2 (low) included respondents who had read or heard about tiger-human conflicts as well as those who had seen evidence of tigers nearby (e.g. pugmark, scat), category 3 (moderate) included respondents who had seen a tiger in the wild, knew somebody whose livestock had been attacked by a tiger, and/or had a friend, neighbour, or relative that had been threatened or attacked by a tiger, category 4 (high) included respondents whose livestock were killed by tigers, and category 5 (very high) included respondents who had been threatened directly by a tiger. If a respondent reported multiple interactions with tigers (e.g. read about tigerhuman conflict and livestock killed by tiger) we used the 
category (1-5) corresponding to the greater degree of interaction with a tiger.

We used maximum likelihood estimation to calculate model parameters. Parameter significance was estimated from bias-corrected bootstrap 95\% confidence intervals based on 2,00o bootstrap samples (Preacher \& Hayes, 2008). The standardized root mean square residual and comparative fit index were used to assess the goodness-of-fit of our model to the data. Structural equation modelling was performed using Amos v. 18 (SPSS Inc., Chicago, USA). We used PASW v. 18 (SPSS Inc., Chicago, USA) to compute Cronbach's alpha reliability coefficients for each set of items composing the belief and perception variables in the final model.

\section{Results}

\section{Characteristics of respondents}

The survey was completed by 499 of 500 individuals contacted; one individual opted not to participate. Average age of respondents was $33.7(15-59)$ years and nearly $37 \%$ were male. Respondents were predominantly female as many men leave Chitwan to work in urban centres in Nepal or elsewhere (Bohra \& Massey, 2009). Respondents ranged in ethnic background, including high caste Hindu, hill Tibetoburmise, lower caste Hindu, Newar, Terai Tibetoburmise, and other Indian castes. Respondents were crop farmers (51\%), livestock producers/keepers (0.5\%), mixed farmers (i.e. crop and livestock farmers, $18 \%)$, business owners (3\%), business employees (8\%), daily wage labourers $(2 \%)$, students $(15 \%)$, and various other occupations $(2.5 \%)$. They had a range of education levels ranging from none $(31 \%)$ to post graduate degrees $(1 \%)$.

\section{Past interactions with tigers}

Interactions between respondents and tigers varied but a large majority of respondents experienced low to moderate levels of interaction with tigers (72\%). Approximately $11 \%$ reported no direct or indirect interactions with tigers and $17 \%$ of respondents reported that a tiger had attacked their livestock (high) or threatened them directly (very high). Nearly $82 \%$ of respondents interacted with tigers on multiple occasions.

\section{Beliefs and perceptions about tigers}

A majority of respondents (59-91\%) associated tigers with cultural, religious, economic (i.e. tourism), ecological and existential benefits. However, nearly $40 \%$ of respondents believed tigers were a nuisance and that there was not enough room for both tigers and people in the nearby forests. A majority of respondents believed that negative encounters with tigers have occurred for a long time (73\%) but agreed that the risks from tigers were avoidable ( $71 \%)$ and something that local people could adapt to over time $(65 \%)$. Nearly two-thirds of respondents agreed that risks from tigers were understood by government officials (63\%) but only $45 \%$ believed officials were satisfactorily addressing the risks. Proportions were approximately the same for those who believed the number of conflicts with tigers had decreased $(36 \%)$, stayed the same $(31 \%)$, or increased (33\%) over the previous 10 years. The proportion of respondents who thought that the risks of living near tigers outweighed the benefits (39\%) was much larger than the proportion of those who thought the benefits outweighed the risks (12\%).

In general, respondents perceived greater cognitive risk (i.e. likelihood) than affective risk (i.e. worry) of attacks by tigers on pets and livestock. Some respondents reported high levels of cognitive risk despite low levels of affective risk perception. Yet, in nearly all cases high levels of affective risk were accompanied by high levels of cognitive risk perception. This relationship was strongest in situations where human safety was at risk. The proportions of respondents who perceived cognitive and affective risk of tiger attacks on someone in their village and tiger attacks on them or someone in their family were comparatively equal (Fig. 3a-d).

\section{Preferred future tiger population size}

The distribution of respondents' preferences for future tiger population size was nearly uniform. An equal proportion of respondents $(40 \%)$ preferred fewer tigers and more tigers in nearby forests over the next 10 years compared to 2010.

\section{Structural equation model}

The initial model $\left(\chi^{2}=1,102.83, \mathrm{df}=261\right)$ fitted the empirical data poorly as the standardized root mean square residual was $>0.8$ and the comparative fit index was $<$ o.9. Thus, we re-specified the model post hoc based on modification indices and standardized factor loadings. Modification indices $>100$ indicated that beliefs about tigers were better explained using one latent variable measuring beneficial attributes and one latent variable measuring undesirable attributes. Beliefs about tiger-related risks were also better explained using two latent variables: government poorly manages tiger-related risks and people are vulnerable to these risks (Table 1 ). Belief about the balance of benefits compared to the risks of having tigers nearby loaded adequately (standardized factor loading $>0.5$ ) as a beneficial attribute (Table 1) rather than a belief about tiger-related risks. Beliefs about the religious 
(a) Tiger will attack respondent's pets (\%)

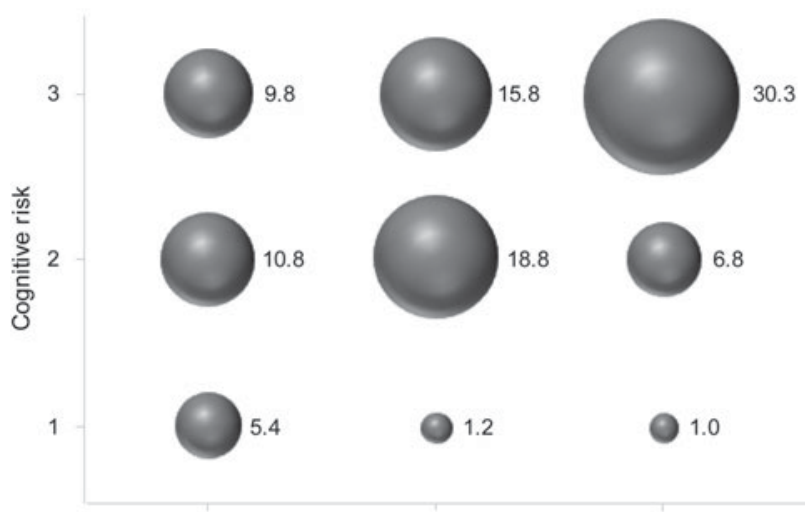

(c) Tiger will attack someone in respondent's village (\%)

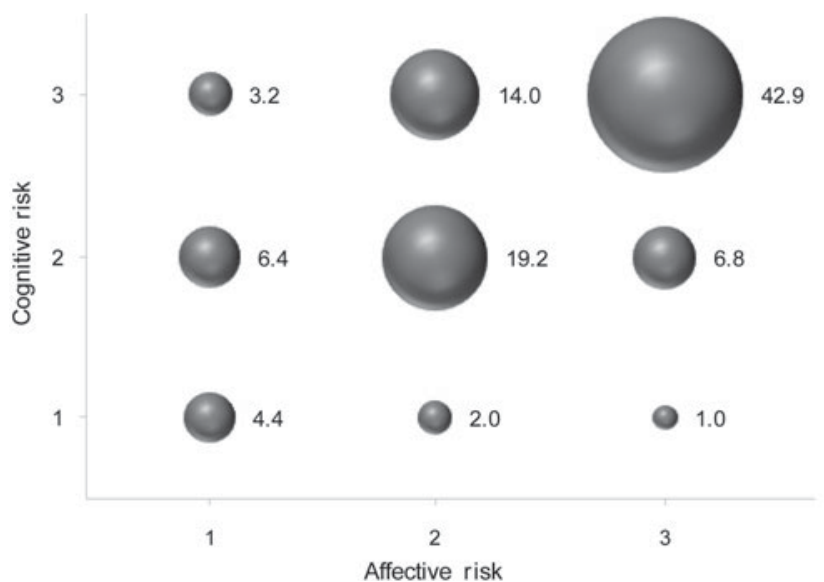

(b) Tiger will attack respondent's farm animals (\%)

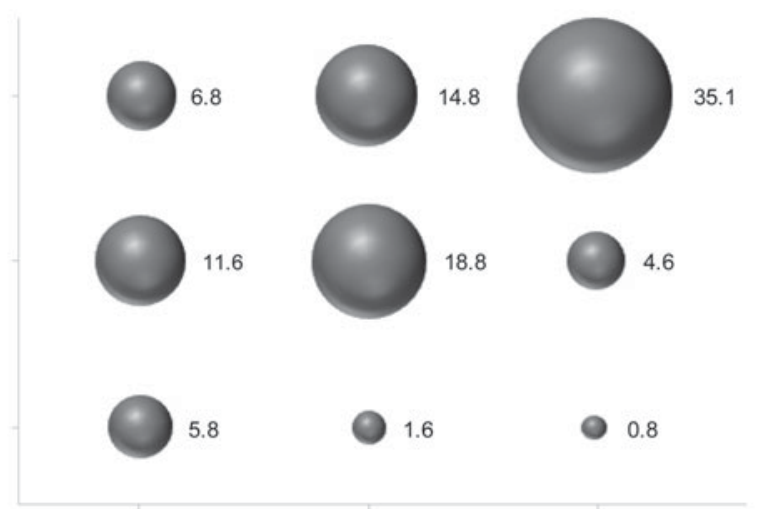

(d) Tiger will attack respondent or someone in respondent's family (\%)

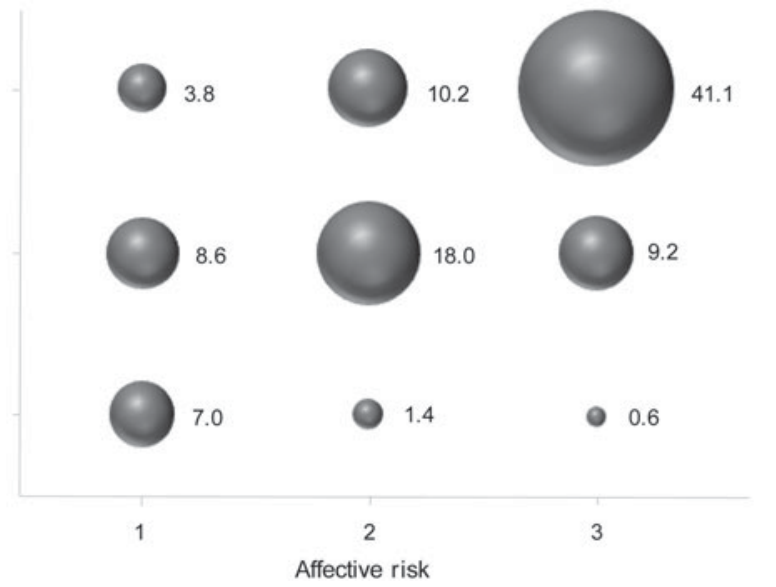

FIG. 3 The percentage of respondents who expressed varying degrees of affective (1, not worried; 2, somewhat worried; 3 , very worried) and cognitive risk (1, not likely; 2, somewhat likely; 3 , very likely) towards tiger attacks on (a) their pets, (b) their livestock,

(c) someone in their village, and (d) themselves or someone in their family.

importance of tigers, the duration that the individual has been exposed to risks from tigers, and the rate of change in exposure to risks from tigers were removed from the model as they did not load adequately on any of the latent variables. The reliability of each set of items composing the belief and perception variables was acceptable (i.e. $>0.65$, Vaske, 2008 ) in the re-specified model (Table 1). Results from the re-specified model $\left(\chi^{2}=622.13, \mathrm{df}=188\right)$ adequately fit the data as the standardized root mean square residual $=0.07$ and comparative fit index $=0.91$.

\section{Determinants of preferred future tiger population size}

There was a significant direct effect in 10 of 20 paths between model variables (Fig. 4). Past interactions with tigers had a significantly positive relationship with affective risk perception but was not related to any other variable. Additionally, the indirect effect (i.e. mediated effect) of interactions with tigers on preferences for future tiger population size was insignificant (Table 2), leading us to reject Hypothesis 1. Beliefs about tigers and tiger-related risks strongly influenced affective and cognitive risk perceptions (Fig. 4), which supports Hypothesis 2. However, risk perceptions did not have a significant direct effect on preferences for future tiger population size, leading us to reject Hypothesis 3. Beliefs about benefits of having tigers nearby had the greatest effect on preferences (Fig. 4). Respondents who preferred fewer tigers in the future were less likely to associate tigers with beneficial attributes, and more likely to associate tigers with undesirable attributes. These respondents were also less likely to believe that risks from tigers are avoidable and that people can adapt to risks from tigers over time. Additionally, they were less likely to believe that risks from tigers in Chitwan are understood and satisfactorily addressed by government officials.

\section{Discussion}

Our model results affirm the idea that human cognitions and emotions towards carnivores are complex and interrelated (Fulton et al., 1996). The hierarchical relationships among variables would have been missed if a multiple linear 
TABLE 1 Reliability and confirmatory factor analysis of latent variables used in the final structural equation model.

\begin{tabular}{|c|c|c|}
\hline Latent variable/survey item & $\begin{array}{l}\text { Factor } \\
\text { loading }\end{array}$ & $\begin{array}{l}\text { Cronbach's } \\
\text { alpha }\end{array}$ \\
\hline Beneficial attributes associated with tigers & & 0.76 \\
\hline Do you agree that your village will benefit from more tourism if tigers are in the nearby forests? & 0.51 & \\
\hline Do you agree that tigers should stay in the nearby forests because they keep the forests healthy? & 0.73 & \\
\hline $\begin{array}{l}\text { Do you agree that tigers are an important part of your culture \& should continue roaming the } \\
\text { nearby forests? }\end{array}$ & 0.62 & \\
\hline $\begin{array}{l}\text { Do you agree that tigers were in Chitwan before humans \& have the right to live in the nearby } \\
\text { forests alongside humans? }\end{array}$ & 0.54 & \\
\hline Does it please you just knowing that tigers exist in the nearby forests? & 0.72 & \\
\hline Do you think that the benefits of living near tigers are greater than, equal to, or less than the risks? ${ }^{2}$ & 0.59 & \\
\hline Undesirable attributes associated with tigers & & 0.74 \\
\hline Do you agree that tigers are a nuisance \& should be kept out of the nearby forests at all costs? & 0.84 & \\
\hline $\begin{array}{l}\text { Do you agree that there is not enough room for both tigers \& humans to live in Chitwan so tigers } \\
\text { should leave the nearby forests? }\end{array}$ & 0.7 & \\
\hline Government poorly manages tiger-related risks & & 0.66 \\
\hline Are the risks from tigers in Chitwan understood by the government or government officials? ${ }^{2}$ & 0.76 & \\
\hline $\begin{array}{l}\text { Are the risks from tigers in Chitwan being satisfactorily addressed by the government or } \\
\text { government officials? }\end{array}$ & 0.64 & \\
\hline People are vulnerable to tiger-related risks & & 0.73 \\
\hline Are the risks from tigers something people living in Chitwan can adapt to over time? ${ }^{2}$ & 0.84 & \\
\hline Are risks from tigers avoidable ${ }^{2}$ & 0.68 & \\
\hline Perceived affective risk of tiger attack & & 0.89 \\
\hline How worried are you that tigers from the nearby forests will attack your pets? & 0.64 & \\
\hline How worried are you that tigers from the nearby forests will attack your farm animals? & 0.8 & \\
\hline How worried are you that tigers from the nearby forests will attack someone in your village? & 0.9 & \\
\hline How worried are you that tigers from the nearby forests will attack you or someone in your family? & 0.91 & \\
\hline Perceived cognitive risk of tiger attack & & 0.89 \\
\hline How likely is it that tigers from the nearby forests will attack your pets? & 0.71 & \\
\hline How likely is it that tigers from the nearby forests will attack your farm animals? & 0.84 & \\
\hline How likely is it that tigers from the nearby forests will attack someone in your village? & 0.88 & \\
\hline How likely is it that tigers from the nearby forests will attack you or someone in your family? & 0.85 & \\
\hline
\end{tabular}

${ }^{1}$ Factor loadings were standardized and were all significant at $\mathrm{P}<0.05$

${ }^{2}$ Items were reverse coded

regression was used to evaluate the data, as in some other studies on local attitudes towards wildlife (Kaczensky et al., 2004; Lischka et al., 2008). In this study, we hypothesized that interactions with tigers (Hypothesis 1) and perceptions of tiger-related risks (Hypothesis 3 ) would affect preferences for future tiger population size. This was not the case, however, suggesting that decreasing the frequency of negative encounters with tigers (e.g. translocating a conflict-prone tiger) and perceptions of tiger-related risks (e.g. campaigns to communicate the relatively low probability of tiger attacks) may only have a small effect on preferences for tigers. In contrast, we found that preferences for future tiger population size were primarily driven by beliefs about tigers and tiger-related risks, not unlike Bruskotter et al. (2009) who found that similar cognitive factors were related to the acceptability of specific management actions towards wolves. Beliefs about tigers and tigerrelated risks also shaped perceptions of tiger-related risks (Hypothesis 2), suggesting that these beliefs are higher-order cognitions that strongly determine how people relate to tigers.

\section{Beliefs about tigers}

Beliefs about tigers in Chitwan reflect changes in socialeconomic conditions. For example, tourism has grown to become a powerful industry in Chitwan, with 836 entry permits to the Park sold in 1974 increasing to 113,788 in 2009 (Curry et al., 2001; GoN, 2009). This may explain why 50\% more respondents agreed that tigers should stay in nearby forests because they attract tourists than the number who agreed that tigers should stay because they keep the forests healthy. However, tigers regulate ungulate populations (Terborgh et al., 1999) that, if unchecked, may eat crops in nearby agricultural fields more frequently and to a greater extent. Crop raiding by protected fauna has already been identified as a major source of resentment among local people towards the Park (UNEP/WCMC, 2008). Education 


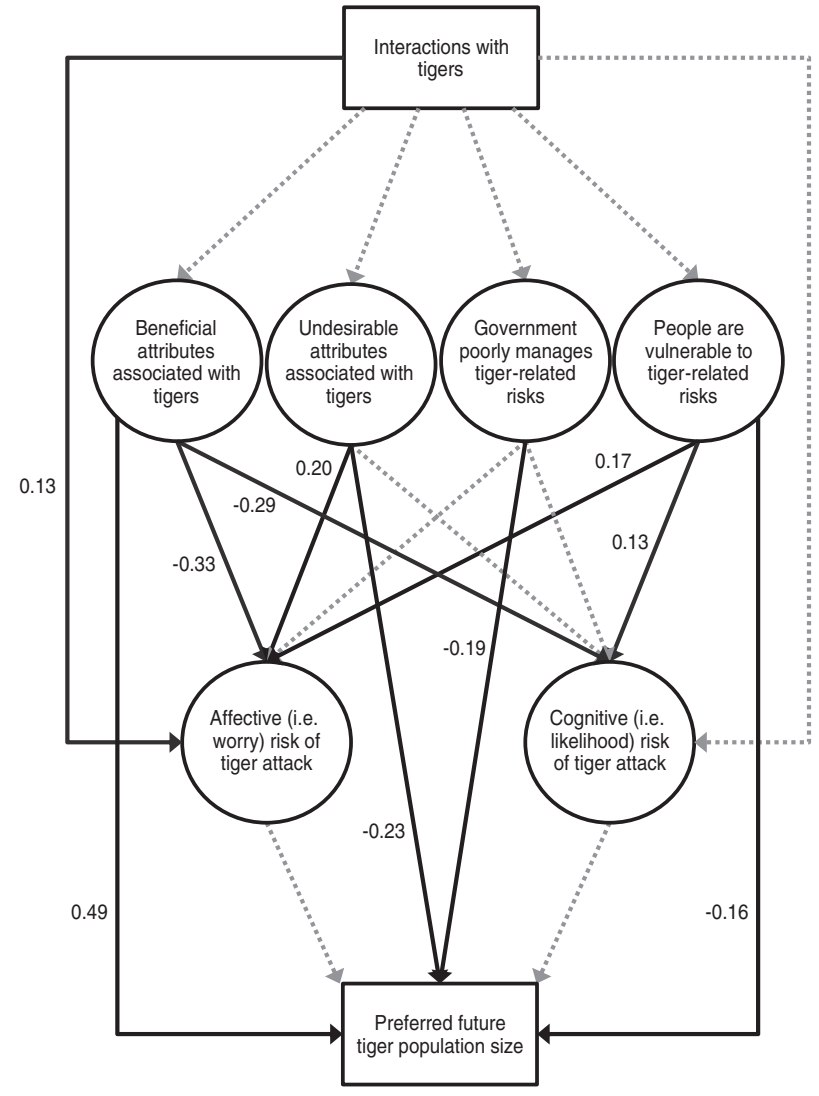

FIG. 4 Path diagram used in final structural equation model. See text and Table 1 for definitions of variables. Solid black lines between variables indicate significant direct effects $(\mathrm{P}<0.05)$ with standardized regression coefficients shown to the left of line. Dashed grey lines indicate no significant direct effect. Correlation between beneficial attributes associated with tigers and undesirable attributes associated with tigers is -0.527 $(\mathrm{P}<0.05)$. Correlation between government poorly manages tiger-related risks and people are vulnerable to tiger-related risks is $-0.054(\mathrm{P}>0.05)$. Correlation between affective risk of tiger attack and cognitive risk of tiger attack is $0.576(\mathrm{P}<0.05)$.

programmes that target specific beliefs may positively condition (Zinn et al., 2008) local people to view larger tiger populations in terms of their beneficial contributions to people (e.g. ecotourism revenue), society (e.g. cultural significance) and the environment (e.g. ecological value) than merely as threats to livelihood and safety.

Assessing the effect of beliefs about carnivores on preferred future carnivore population size is important, as conservation actions that fail to account for differences in local beliefs with respect to region and species may not effectively increase the capacity of local people to support those carnivores. For instance, Kissui (2008) found that cultural sentiments of local people towards African lions Panthera leo, leopards Panthera pardus and spotted hyaenas influenced the vulnerability of those species to retaliatory killing. Therefore carnivore persecution, influenced by subjective beliefs, may continue despite reductions in livestock predation.
TABLE 2 Indirect and total effects of independent variables on preferred future tiger population size (the dependent variable) determined from the structural equation model.

\begin{tabular}{llll}
\hline Dependent/independent variables & $\begin{array}{l}\text { Indirect }_{\text {effects }}{ }^{1} \\
\text { Preferred future tiger }\end{array}$ & $\begin{array}{l}\text { Total } \\
\text { effects }\end{array}$ & $R^{2}$ \\
population size & & & 0.51 \\
$\begin{array}{l}\text { Past interactions with tigers } \\
\text { Beneficial attributes associated }\end{array}$ & 0.02 & & \\
$\quad$ with tigers & 0.02 & $0.51^{2}$ & \\
$\quad \begin{array}{l}\text { Undesirable attributes associated } \\
\text { with tigers }\end{array}$ & -0.01 & $-0.24^{2}$ & \\
$\begin{array}{l}\text { Government poorly manages } \\
\text { tiger-related risks }\end{array}$ & 0.01 & $-0.19^{2}$ & \\
$\begin{array}{l}\text { People are vulnerable to } \\
\text { tiger-related risks }\end{array}$ & -0.01 & $-0.17^{2}$ & \\
$\begin{array}{l}\text { Perceived affective risk of } \\
\text { tiger attack }\end{array}$ & & -0.01 & \\
$\begin{array}{l}\text { Perceived cognitive risk of } \\
\text { tiger attack }\end{array}$ & & -0.08 & \\
\hline
\end{tabular}

${ }^{1}$ Standardized regression coefficients

${ }^{2}$ Significant at $\mathrm{P}<0.05$

\section{Beliefs about tiger-related risks}

Local people living near and among carnivores incur the greatest costs from these species (Wang \& Macdonald, 2006; Gurung et al., 2008). Yet management responsibility of threatened carnivores typically rests with government or conservation agencies rather than local communities (Treves et al., 2006). Our results from Chitwan underscore a need for government and conservation agencies to supplement mitigation of human-tiger conflicts through direct intervention (e.g. translocating or killing a conflictprone tiger) by building local trust and satisfaction in agency programmes (Slovic, 1993). This is particularly important in developing rural areas where local people often have limited options with which to respond to human-wildlife conflicts (Ogada et al., 2003).

Respondent belief that people are vulnerable to tigerrelated risks reflects a perceived inability to control one's environment (Ajzen, 2002). This sense of vulnerability combined with perceived inefficacy of government and conservation agencies may compel local people to resolve human-carnivore conflicts by illegal means (Treves et al., 2002). Employing a number of conservation tools, including proactive education and awareness programmes, effective compensation programmes (Dickman et al., 2011) and carnivore-response teams with a contingent of local people (Gurung et al., 2008), may increase satisfaction in government/conservation agencies and reduce the sense of vulnerability among local people to carnivore-related risks. In addition, incorporating local communities as partners in conservation planning and implementation 
may increase the capacity of those communities to cohabit with carnivores (Treves et al., 2006).

\section{Interactions with tigers and risk perceptions}

Previous wildlife acceptance capacity studies have alluded to the strong effect that past experiences with carnivores, particularly negative interactions (e.g. livestock attack), have on preferences for carnivore population size (Riley \& Decker, 200ob; Bruskotter et al., 2009). However, these studies focused on perceived impacts rather than an explicit measure of past experience with carnivores because actual human-carnivore interactions at the study sites (Montana and Utah, USA) were so infrequent. By explicitly measuring past experiences we found that the proportion of people in Chitwan who had direct interactions with tigers (i.e. high impact) was surprisingly high, probably similar to many other places where human-carnivore conflicts are severe.

People in Chitwan have lived in close proximity to tigers for hundreds of years (McLean, 1999) and frequently enter the forests to collect natural resources for subsistence or for sale in nearby markets (Straede \& Treue, 2006). Thus, tiger-human interactions in Chitwan are generally more consistent and direct than those between carnivores and people in developed countries (Manfredo et al., 2009). After such long and persistent exposure to threats posed by tigers, people in Chitwan may have internalized the risks into their day-to-day lives (Slovic, 1987), which may explain why past interactions with tigers and risk perceptions did not influence preferences for future tiger population size. Whereas, in Montana, USA, where one fatality from cougar attack in the 2oth century has been documented, perceptions of cougar-related risks were significantly related to preferences for future cougar population size (Riley \& Decker, 2000a). Similar research conducted in other areas facing similar human-carnivore conservation issues would be useful in refining model variables and testing the external validity of our model.

\section{Conclusions}

Human-carnivore conflicts are predicted to increase in developing regions of the world (Baillie et al., 2004), which will probably lead to increased rates of retaliatory killings and additional burdens on limited conservation resources that already suffer from monetary and personnel shortages (Treves et al., 2006). Our novel psychological framework can help address current and future conservation challenges because it (1) integrates an expansive and generalized set of concepts, (2) enables the identification of conservation interventions that foster coexistence between people and conflict-prone carnivores, and (3) is applicable to species in other parts of the world. For instance, in places with human-lion conflicts using our framework could inform policies that address the beliefs and perceptions germane to local preferences for future lion population size, such as implementing education programmes in Tanzania, where human-lion conflict is severe (Chardonnet et al., 2010), to reduce the belief that attacks on people are unavoidable. Moreover, focusing conservation efforts on people who prefer smaller future populations of threatened carnivores may be an effective means of distributing limited resources, reducing human-carnivore conflicts and engaging local communities in conservation.

\section{Acknowledgements}

We acknowledge our colleagues in the Center for Systems Integration and Sustainability at Michigan State University and the Institute for Social and Environmental ResearchNepal in Chitwan for their contributions to this article. Research was supported by a grant from the U.S. Fish and Wildlife Service Rhinoceros and Tiger Conservation Fund, National Science Foundation (Partnerships in International Research and Education, Dynamics of Coupled Natural and Human Systems Program), and fellowships from Michigan State University and NASA's Earth and Space Science programme.

\section{References}

AJZen, I. (1991) The theory of planned behavior. Organizational Behavior and Human Decision Processes, 50, 179-211.

AjZen, I. (2002) Perceived behavioral control, self-efficacy, locus of control, and the theory of planned behavior. Journal of Applied Social Psychology, 32, 665-683.

Axinn, W.G. \& Ghimire, D.J. (2007) Social Organization, Population, and Land Use. Population Studies Center, Institute for Social Research, University of Michigan, Ann Arbor, USA.

Baillie, J., Hilton-Taylor, C. \& Stuart, S.N. (eds) (2004) 2004 IUCN Red List of Threatened Species: A Global Species Assessment. IUCN, Gland, Switzerland.

Bohra, P. \& Massey, D.S. (2009) Processes of internal and international migration from Chitwan, Nepal. International Migration Review, 43, 621-651.

Bruskotter, J.T., VAske, J.J. \& Schmidt, R.H. (2009) Social and cognitive correlates of Utah residents' acceptance of the lethal control of wolves. Human Dimensions of Wildlife, 14, 119-132.

Carpenter, L.H., Decker, D.J. \& Lipscomb, J.F. (2000) Stakeholder acceptance capacity in wildlife management. Human Dimensions of Wildlife, 5, 5-19.

CbS (Central Bureau of Statistics) (2001) Population Census 2001: Village Development Committee/Municipalities. Http://www. cbs.gov.np [accessed 1 August 2011].

Chardonnet, P., Soto, B., Fritz, H., Crosmary, W., DrouetHoguet, N., Mésochina, P. et al. (2010) Managing the Conflicts Between People and Lion: Review and Insights from the Literature and Field Experience. Wildlife Management Working Paper 13. Food and Agriculture Organization of the UN, Rome, Italy.

Curry, B., Moore, W., Bauer, J., Cosgriff, K. \& Lipscombe, N. (2001) Modelling impacts of wildlife tourism on animal 
communities: a case study from Royal Chitwan National Park, Nepal. Journal of Sustainable Tourism, 9, 514-529.

Decker, D.J. \& Purdy, K.G. (1988) Toward a concept of wildlife acceptance capacity in wildlife management. Wildlife Society Bulletin, 16, 53-57.

Dickman, A.J., Macdonald, E.A. \& Macdonald, D.W. (2011) A review of financial instruments to pay for predator conservation and encourage human-carnivore coexistence. Proceedings of the National Academy of Sciences of the USA, 108, 13937-13944.

Eagly, A.H. \& Chaiken, S. (1993) The Psychology of Attitudes. Harcourt Brace Jovanovich College Publishers, Fort Worth, USA.

Fulton, D.C., Manfredo, M.J. \& Lipscomb, J. (1996) Wildlife value orientations: a conceptual and measurement approach. Human Dimensions of Wildlife, 1, 24-47.

GoN (Government of NePAL) (2009) Nepal Tourism Statistics 2009 Annual Statistical Report. Ministry of Tourism and Civil Aviation, Kathmandu, Nepal.

Gore, M.L. \& KNUTH, B.A. (2009) Mass media effect on the operating environment of a wildlife-related risk-communication campaign. Journal of Wildlife Management, 73, 1407-1413.

Gore, M.L., Knuth, B.A., Curtis, P.D. \& Shanahan, J.E. (2006) Stakeholder perceptions of risk associated with human-black bear conflicts in New York's Adirondack Park campgrounds: implications for theory and practice. Wildlife Society Bulletin, $34,36-43$.

Gurung, B., Smith, J.L.D., McDougal, C., Karki, J.B. \& BARLOW, A. (2008) Factors associated with human-killing tigers in Chitwan National Park, Nepal. Biological Conservation, 141, 3069-3078.

Hu, L. \& Bentler, P.M. (1999) Cutoff criteria for fit indexes in covariance structure analysis: conventional criteria versus new alternatives. Structural Equation Modeling: A Multidisciplinary Journal, 6, 1-55.

Inskip, C. \& Zimmermann, A. (2009) Human-felid conflict: a review of patterns and priorities worldwide. Oryx, 43, 18-34.

Kaczensky, P., Blazic, M. \& Gossow, H. (2004) Public attitudes towards brown bears (Ursus arctos) in Slovenia. Biological Conservation, 118, 661-674.

Kasperson, R.E., Renn, O., Slavic, P., Brown, H.S., Emel, J., GobLe, R. et al. (1988) The social amplification of risk: a conceptual framework. Risk Analysis, 8, 177-187.

KeLleRT, S.R. (1985) Social and perceptual factors in endangered species management. Journal of Wildlife Management, 49, 528-536.

KIsSUI, B.M. (2008) Livestock predation by lions, leopards, spotted hyenas, and their vulnerability to retaliatory killing in the Maasai steppe, Tanzania. Animal Conservation, 11, 422-432.

LAURIE, A. (1982) Behavioural ecology of the greater one-horned rhinoceros (Rhinoceros unicornis). Journal of Zoology, 196, 307-341.

LischKa, S.A., Riley, S.J. \& Rudolph, B.A. (2008) Effects of impact perception on acceptance capacity for white-tailed deer. Journal of Wildlife Management, 72, 502-509.

Manfredo, M.J., Vaske, J.J., Brown, P.J., Decker, D.J. \& Duke, E. A. (2009) Wildlife and Society: The Science of Human Dimensions. Island Press, Washington, DC, USA.

Marker, L., Mills, M. \& Macdonald, D. (2003) Factors influencing perceptions of conflict and tolerance toward cheetahs on Namibian farmlands. Conservation Biology, 17, 1290-1298.

McLean, J. (1999) Conservation and the impact of relocation on the Tharus of Chitwan, Nepal. Himalayan Research Bulletin, 19, 8.

NSD (Nepal Survey Department) (1996) Ministry of Land Reform and Management. Survey Department. Http://www.dos.gov.np [accessed 15 May 2012].
Ogada, M.O., Woodroffe, R., Oguge, N.O. \& Frank, L.G. (2003) Limiting depredation by African carnivores: the role of livestock husbandry. Conservation Biology, 17, 1521-1530.

Peyton, B., Bull, P., Reis, T. \& Visser, L. (2001) Public Views on Bear and Bear Management in the Lower Peninsula of Michigan. Report to the Michigan Department of Natural Resources, Wildlife Division, Lansing, USA.

Preacher, K.J. \& Hayes, A.F. (2008) Asymptotic and resampling strategies for assessing and comparing indirect effects in multiple mediator models. Behavior Research Methods, 40, 879-891.

Reisinger, Y. \& Mavondo, F. (2007) Structural equation modeling. Journal of Travel and Tourism Marketing, 21, 41-71.

RiLeY, S.J. (1998) Integration of environmental, biological, and human dimensions for management of mountain lions (Puma concolor) in Montana. PhD thesis. Cornell University, Ithaca, USA.

Riley, S.J. \& Decker, D.J. (200oa) Risk perception as a factor in wildlife stakeholder acceptance capacity for cougars in Montana. Human Dimensions of Wildlife, 5, 50-62.

Riley, S.J. \& Decker, D.J. (200ob) Wildlife stakeholder acceptance capacity for cougars in Montana. Wildlife Society Bulletin, 28, 931-939.

Romañach, S.S., Lindsey, P.A. \& Woodroffe, R. (2007) Determinants of attitudes towards predators in central Kenya and suggestions for increasing tolerance in livestock dominated landscapes. Oryx, 41, 185-195.

Saberwal, V.K., Gibbs, J.P., Chellam, R. \& Johnsingh, A.J.T (1994) Lion-human conflict in the Gir forest, India. Conservation Biology, 8, 501-507.

SCHAfer, J.L. (1999) Multiple imputation: a primer. Statistical Methods in Medical Research, 8, 3-15.

Seidensticker, J., Jackson, P. \& Christie, S. (1999) Riding the Tiger: Tiger Conservation in Human-Dominated Landscapes. Cambridge University Press, Cambridge, UK.

Sharma, U.R. (1990) An overview of park-people interactions in Royal Chitwan National Park, Nepal. Landscape and Urban Planning, 19, 133-144.

SJÖBERG, L. (1998) Worry and risk perception. Risk Analysis, 18, 85-94.

Slovic, P. (1987) Perception of risk. Science, 236, 280-285.

Stovic, P. (1993) Perceived risk, trust, and democracy. Risk Analysis, $13,675-682$.

Straede, S. \& Treue, T. (2006) Beyond buffer zone protection: a comparative study of park and buffer zone products' importance to villagers living inside Royal Chitwan National Park and to villagers living in its buffer zone. Journal of Environmental Management, 78, 251-267.

Terborgh, J., Estes, J.A., Paquet, P., Ralls, K., Boyd-Heger, D., Miller, B.J. \& Noss, R.F. (1999) The role of top carnivores in regulating terrestrial ecosystems. In Continental Conservation: Scientific Foundations of Regional Reserve Networks (eds M.E. Soule \& J. Terborgh), pp. 39-64. Island Press, Washington, DC, USA.

Treves, A., Jurewicz, R.R., Naughton-Treves, L., Rose, R.A., Willging, R.C. \& WYDEVEN, A.P. (2002) Wolf depredation on domestic animals in Wisconsin, 1976-200o. Wildlife Society Bulletin, 30, 231-241.

Treves, A. \& Karanth, K.U. (2003) Human-carnivore conflict and perspectives on carnivore management worldwide. Conservation Biology, 17, 1491-1499.

Treves, A., Wallace, R.B., Naughton-Treves, L. \& Morales, A. (2006) Co-managing human-wildlife conflicts: a review. Human Dimensions of Wildlife, 11, 383-396.

UNEP/WCMC (UN Environment Programme/World Conservation Monitoring Centre) (2008) Royal Chitwan National Park, Nepal. 
Http://www.unep-wcmc-apps.org/sites/wh/pdf/Chitwan.pdf [accessed 10 January 2009].

VASke, J.J. (2008) Survey Research and Analysis: Application in Parks, Recreation and Human Dimensions. Venture Publishing, State College, USA.

Walston, J., Robinson, J.G., Bennett, E.L., Breitenmoser, U., Da Fonseca, G.A.B., Goodrich, J. et al. (2010) Bringing the tiger back from the brink-the six percent solution. PLoS Biology, 8 , 493-506.

Wang, S.W., Lassoie, J.P. \& Curtis, P.D. (2006) Farmer attitudes towards conservation in Jigme Singye Wangchuck National Park, Bhutan. Environmental Conservation, 33, 148-156.

WANG, S.W. \& MACDONALD, D.W. (2006) Livestock predation by carnivores in Jigme Singye Wangchuck National Park, Bhutan. Biological Conservation, 129, 558-565.

Whitt Aker, D., VAske, J.J. \& MANFredo, M.J. (2006) Specificity and the cognitive hierarchy: value orientations and the acceptability of urban wildlife management actions. Society and Natural Resources, 19, 515-530.

Woodroffe, R. (2000) Predators and people: using human densities to interpret declines of large carnivores. Animal Conservation, 3 , 165-173.

Woodroffe, R. (2001) Strategies for carnivore conservation: lessons from contemporary extinctions. In Carnivore Conservation (eds J.L. Gittleman, S. Funk, D.W. Macdonald \& R.K. Wayne), pp. 61-92. Cambridge University Press, New York, USA.
Woodroffe, R. \& Ginsberg, J.R. (1998) Edge effects and the extinction of populations inside protected areas. Science, 280, 21262128.

Woodroffe, R., Thirgood, S. \& Rabinowitz, A. (2005) People and Wildlife: Conflict or Coexistence? Cambridge University Press, New York, USA.

Zinn, H., Manfredo, M. \& Decker, D. (2008) Human conditioning to wildlife: steps toward theory and research. Human Dimensions of Wildlife, 13, 388-399.

Zinn, H.C., Manfredo, M.J. \& Vaske, J.J. (2000) Social psychological bases for stakeholder acceptance capacity. Human Dimensions of Wildlife, 5, 20-33.

\section{Biographical sketches}

Neil Carter studies the complex interrelationships between humans and carnivores, with a particular focus on improving conservation planning. He is also interested in human dimensions of wildlife management, wildlife behaviour and habitat use, and protected area management. SHawn Riley studies human-wildlife interactions, most recently focusing on tolerance of wildlife in various settings, wildlife health management, and how better to integrate insights from ecological and social science in decisions about wildlife management. JIANGUO LIU's research interests include household-environment interactions, complexity of coupled human and natural systems, wildlife ecology, landscape ecology, systems modelling and the science of sustainability. 